\title{
MENGANALISA PONDASI RUMAH RAKIT DARI BAMBU KE PIPA PVC DI SEKITAR SUNGAI MUSI PALEMBANG
}

\author{
Zuul Fitriana Umari \\ Program Studi Teknik Sipil \\ Fakultas Teknik - UTP \\ Email : zuulfitrianaumari@gmail.com
}

Palembang merupakan kota air yang banyak dialiri sungai. Sungai Musi bagi masyarakat palembang sangat vital keberadaanya, sebagi sarana transportasi dan sumber mata pencaharian dengan ikan tangkap. Dengan kondisi geografis seperti ini, beberapa orang penduduk palembang menghuni rumah yang terapung di atas sungai, disebut dengan nama 'rumah rakit'. Sejumlah rumah Rakit merupakan warisan lintas generasi yang tahan dihuni puluhan tahun, meskipun bambu yang mendasari Rakit dan tiang penambat perlu diganti secara periodik. Rumah rakit umumnya menggunakan bahan dari bambu. Maka dari itu penulis membahas masalah tentang landasan rumah rakit yaitu bambu, dan bagaimana jika bambu tersebut diganti dengan bahan pipa PVC (Poly Vinil Chloride). Tujuannya adalah agar didapat bahan alternatif atau pengganti bambu yang menjadi landasan rumah rakit yang cocok, ekonomis, dan efisien untuk digunakan. Dari hasil penelitian dihasilkan, bahwasanya landasan pipa PVC dapat diterapkan sebagai bahan alternatif pengganti bambu pada pembangunan rumah rakit.

Kata kunci : Rumah rakit, bambu, pipa pvc.

Kata Kunci : Rumah rakit, bambu, Pipa PVC.

\section{LATAR BELAKANG}

Rumah rakit Palembang merupakan tempat tinggal tetap (tidak berpindah-pindah) yang terapung. Rumah jenis ini terbuat dari kayu dan bambu dengan atap kajang (nipah), sirap dan belakangan ini menggunakan atap seng (bahan yang lebih ringan). Rumah rakit dibangun di atas sebuah rakit, baik yang terbuat dari rangkaian bambu-bambu. Pintu pada rumah rakit bisanya ada dua, satu menghadap ke sungai dan yang satunya lagi menghadap ke daratan. Jendelanya, biasanya, berada pada sisi kiri dan kanan dinding rumah rakit, tetapi ada juga yang berada di sisi kanan dan kiri pintu masuk rumah.

Rumah rakit merupakan konsep water front city nya Kota Palembang yang bertahan sejak ratusan tahun silam. ( Jelajah Musi, 2010). Dalam sejarahnya, rumah rakit bukan sekadar hunian darurat melainkan juga sebagai rumah untuk mengangkut barang dagangan oleh pedagang dari kawasan Uluan Palembang ke pusat kota, bangunannya sendiri ikut mereka jual setelah sekian lama tertahan berbulan-bulan dipinggiran kota sungai musi. Sejumlah rumah rakit merupakan warisan lintas generasi yang tahan dihuni puluhan tahun, meskipun bambu yang mendasari rakit perlu diganti secara periodik.

Bambu merupakan bahan yang penting dalam pembuatan rumah rakit tetapi akan ada waktunya bambu akan sulit di dapatkan. maka dalam penelitian ini akan di coba untuk melakukan penelitian tentang penggantin bambu sebagai pondasi rumah rakit.

\section{(1). Tujuan Penelitian}

Tujuan penelitian adalah mencari bahan pengganti bambu pada landasan rumah rakit jika tanaman bambu sulit untuk didapatkan.

\section{(2). Ruang Lingkup}

Pada penelitian ini ruang lingkup penelitian yaitu membatasi pada struktur bawah rumah rakit yaitu pondasi berupa bambu yang akan digantikan dengan penggunaan Pipa PVC (Poly Vinil Chloride) sebagai bahan pondasi rumah rakit.
1. TINJAUAN PUSTAKA
(1). Pengertian Rumah Rakit 
Yang dimaksud dengan rumah rakit, pada dasarnya adalah rumah yang merupakan tempat tinggal yang tetap dan terapung. Rumah rakit dibangun di atas sebuah rakit terapung di atas air. Namun akibat dari perubahan pasang naik dan pasang surut Sungai Musi, beberapa rumah rakit ada yang berada antara batas ketinggian air ratarata bila tidak pasang naik dengan tanah. Dengan posisi ini, rumah akan terapung hanya jika sedang pasang naik.. Ruamh rakit tidak hanya berfungsi sebagai tempat tinggal tetapi juga sebagai kegiatan ekonomi. (melayuonline.com).

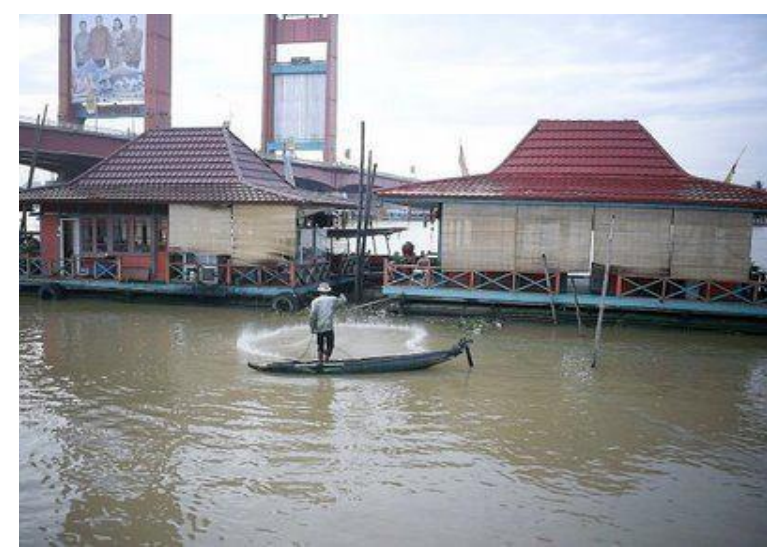

Gambar 1. Rumah Rakit Palembang

\section{(2).Bahan-Bahan pembuatan rumah rakit}

\section{a. Bambu}

Bahan utama pembuatan rumah Rakit adalah Bambu. Bambu yang digunakan adalah bambu jenis manyan. Bambu ini di samping tahan lama juga besar - besar ukuran berkisar antara 2,5" s/d 3" sehingga cukup bagus digunakan sebagai pelampung agar bisa mengambang di atas permukaan air. Di samping bahan untuk membuat bagian bawah rumah Rakit, bambu juga digunakan untuk membuat dinding, yaitu dengan cara dicacah dan direntangkan. (Ensiklopedi Suku Bangsa di Indonesia, 1995)

\section{b. Papan}

Untuk membuat dinding rumah Rakit, selain menggunakan bambu, juga sering menggunakan papan.

\section{c. Ulit (sejenis daun yang dianyam)}

Bahan ini digunakan untuk membuat atap rumah Rakit.

\section{d. Rotan}

Rotan yang digunakan ada dua macam, yaitu rotan selinep dan rotan sago. Rotan selinep adalah rotan kecil yang digunakan untuk mengikat bagian atas rumah Rakit, sedangkan rotan sago adalah rotan yang digunakan untuk mengikat bambu-bambu yang digunakan sebagai bahan pelampung.

\section{(3). Tahapan Pembangunan Rumah Rakit}

\section{a. Persiapan}

Bambu merupakan bahan utama untuk membuat rumah Rakit. Untuk mendapatkan bambu ada dua cara yang dapat dilakukan, yaitu mencari sendiri di hutan atau memesan kepada pedagang bambu. Bambu yang dicari sendiri ke hutan ataupun dipesan kepada pedagang bambu, ukurannya disesuaikan dengan peruntukannya, misalnya untuk pelampung, dinding atau langitlangit.

\section{b. Tahap pembuatan pondasi rumah rakit}

Bagian bawah dari rumah Rakit merupakan bagian terpenting. Bagian ini, menentukan kokoh tidaknya rumah Rakit. Oleh karena itu, pembangunan bagian bawah rumah Rakit dilakukan secara cermat, mulai dari pemilihan bahan (bambu-bambu) sampai pada proses merangkai bahan-bahan tersebut menjadi pelampung. Adapun prosesnya adalah sebagai berikut:

1. Bambu-bambu yang dipersiapkan sebagai pelampung dilubangi pada ujung dan pangkalnya.

2. Setelah itu, kemudian dirangkai dengan memasukkan sepotong kayu sebagai pasak pengikat. Setiap rangkaian bambu terdiri dari 8 sampai 12 batang bambu. Proses merangkai batang bambu ini disebut mengarang.

3. Jumlah rangkaian batang bambu yang dibuat berjumlah 6 sampai 8 ikatan.

4. Rangkaian tersebut kemudian ditumpuk menjadi satu ikatan yang tersusun. Susunan bambu tersebut berjumlah 48 sampai 96 batang bambu, kadang-kadang digenapkan sampai 100 batang bambu Agar ikatan pada rangkaian bambu tersebut semakin kuat, maka selain menggunakan /pasak pengikat/, juga diikat dengan menggunakan rotan.

5. Kemudian rangkaian bambu tersebut dihubungkan dengan balok-balok kayu yang dipasang melintang sehingga menjadi sebuah lanting (lantai).

6. Agar ikatan semakin kuat, pada jarak antara setengah sampai satu setengah meter, lanting tersebut diikat dengan rotan. 
7. Selesainya pengikatan pada lanting, maka pembuatan bagian bawah rumah Rakit sudah selesai.

\section{(4). Pembebanan}

Dalam merencanakan beban untuk rumah dan gedung diharuskan memperhatikan penggunaan beban-beban yang diijinkan dalam perencanaan. (Beton Prategang, 2001).

\section{a. Beban Mati}

Beban mati merupakan berat dari semua bagian dari suatu gedung yang bersifat tetap, termasuk segala unsur tambahan, penyelesaianpenyelesaian, mesin-mesin serta peralatan tetap yang merupakan bagian yang tak terpisahkan dari gedung itu.

\section{Berat Sendiri}

Berat sendiri merupakan berat dari komponen-komponen Bangunan atau gedung. Dari beberapa komponen gedung yang harus ditinjau didalam menentukan beban mati dari suatu gedung, harus diambil menurut table seperti dibawah ini :

Tabel 1. Berat Sendiri Bahan Bangunan

\begin{tabular}{|l|l|l|}
\hline No & Bahan Bangunan & Berat $\left(\mathrm{kg} / \mathrm{m}^{3}\right)$ \\
\hline 1 & Baja & 7.850 \\
\hline 2 & Batu Alam & 2.600 \\
\hline 3 & $\begin{array}{l}\text { Batu belah, batu bulat, batu } \\
\text { gunung (berat tumpuk) }\end{array}$ & 1.500 \\
\hline 4 & Batu karang (berat tumpuk) & 700 \\
\hline 5 & Batu Pecah & 1.450 \\
\hline 6 & Batu tuang & 7.250 \\
\hline 7 & Beton & 2.200 \\
\hline 8 & Beton bertulang & 2.400 \\
\hline 9 & Kayu (kelas I) & 1.000 \\
\hline 10 & $\begin{array}{l}\text { Kerikil, koral (kering udara } \\
\text { sampai lembab, tanpa diayak) }\end{array}$ & 1.650 \\
\hline 11 & Pasangan bata merah & 1.700 \\
\hline 12 & $\begin{array}{l}\text { Pasangan batu belah, batu bulat, } \\
\text { batu gunung }\end{array}$ & 2.200 \\
\hline 13 & Pasangan batu cetak & 2.200 \\
\hline 14 & Pasangan batu karang & 1.450 \\
\hline 15 & $\begin{array}{l}\text { Pasir (kering udara sampai } \\
\text { lembab) }\end{array}$ & 1.600 \\
\hline 16 & Pasir (jenuh air) & 1.800 \\
\hline 17 & $\begin{array}{l}\text { Pasir kerikil, koral (kering udara } \\
\text { sampai lembab) }\end{array}$ & $\begin{array}{l}\text { Tanah, lempung dan lanau } \\
\text { kering udara sampai lembab) }\end{array}$ \\
\hline 18 & 1.700 \\
\hline 19 & $\begin{array}{l}\text { Tanah, lempung dan lanau } \\
\text { (basah) }\end{array}$ \\
\hline
\end{tabular}

Sumber : Beton Prategang, 2001
Tabel 2. Berat Sendiri Komponen Gedung

\begin{tabular}{|c|c|c|}
\hline No & Komponen Gedung & Berat $\left(\mathrm{kg} / \mathrm{m}^{2}\right)$ \\
\hline 1 & $\begin{array}{l}\text { Adukan, per cm tebal: } \\
\text { - dari semen } \\
\text { - dari kapur, semen merah atau tras }\end{array}$ & $\begin{array}{l}21 \\
17\end{array}$ \\
\hline 2 & $\begin{array}{l}\text { Aspal, termasuk bahan-bahan mineral } \\
\text { penambah, / cm tebal }\end{array}$ & 14 \\
\hline 3 & $\begin{array}{l}\text { Dinding pasangan bata merah } \\
\text { - Satu batu } \\
\text { - Setengah batu }\end{array}$ & $\begin{array}{l}450 \\
250\end{array}$ \\
\hline 4 & $\begin{array}{l}\text { Dinding pasangan batako: } \\
\text { Berlubang } \\
\text { - tebal dinding } 20 \mathrm{~cm}(\mathrm{HB} 20) \\
\text { - tebal dinding } 10 \mathrm{~cm} \text { (HB10) } \\
\text { Tanpa lubang } \\
\text { - tebal dinding } 15 \mathrm{~cm} \\
\text { - tebal dinding } 10 \mathrm{~cm}\end{array}$ & $\begin{array}{l}200 \\
120 \\
300 \\
200\end{array}$ \\
\hline 5 & $\begin{array}{l}\text { Langit-langit dan dinding (termasuk } \\
\text { rusuk-rusuknya, tanpa penggantung } \\
\text { langit-langit atau pengaku),terdiri dari: } \\
\text { - semen asbes (eternity dan bahan } \\
\text { lain sejenis), maks tebal } 4 \mathrm{~mm} \\
\text { - kaca, dengan tebal 3-5 mm }\end{array}$ & $\begin{array}{l}11 \\
10\end{array}$ \\
\hline 6 & $\begin{array}{l}\text { Lantai kayu sederhana dengan balok } \\
\text { kayu, tanpa langit-langit dengan } \\
\text { bentang maks } 200 \mathrm{~kg} / \mathrm{m}^{2}\end{array}$ & 40 \\
\hline 7 & $\begin{array}{l}\text { Penutup genting dengan reng dan } \\
\text { usuk/kaso } / \mathrm{m}^{2} \text { bidang atap }\end{array}$ & 50 \\
\hline 8 & $\begin{array}{llll}\text { Penutup sirap dengan reng dan } \\
\text { usuk/kaso } / \mathrm{m}^{2} \text { bidang atap }\end{array}$ & 40 \\
\hline 9 & $\begin{array}{l}\text { Penutup atap seng gelombang (BJLS- } \\
\text { 25) tanpa gordeng }\end{array}$ & 10 \\
\hline 10 & $\begin{array}{l}\text { Penutup lantai ubin semen Portland, } \\
\text { teraso dan beton tanpa adukan, / cm } \\
\text { tebal }\end{array}$ & 24 \\
\hline 11 & Semen asbes gelombang (tebal $5 \mathrm{~mm}$ ) & 11 \\
\hline
\end{tabular}

Sumber : Beton Prategang, 2001

\section{b. Beban Hidup}

Beban hidup yang diperhitungkan harus benar-benar diperhitungkan terutama beban hidup pada lantai gedung dan atap gedung. Beban hidup bagian atap serta pada struktur tudung (canopy) yang dapat dicapai dan dibebani oleh orang, harus diambil minimum sebesar 100 $\mathrm{kg} / \mathrm{m}^{2}$ bidang datar.

Tabel 3. Beban Hidup Pada Lantai Gedung

\begin{tabular}{|l|l|l|}
\hline NO & Beban Hidup & Berat $\left(\mathrm{kg} / \mathrm{m}^{2}\right)$ \\
\hline 1 & $\begin{array}{l}\text { Lantai dan tangga rumah tinggal, } \\
\text { kecuali yang disebut dalam no 2 }\end{array}$ & 200 \\
\hline 2 & $\begin{array}{l}\text { Lantai dan tangga rumah tinggal } \\
\text { sederhana dan gudang tidak penting } \\
\text { yang bukan untuk toko, pabrik atau } \\
\text { bengkel }\end{array}$ & 125 \\
\hline
\end{tabular}




\begin{tabular}{|l|l|l|}
\hline 3 & $\begin{array}{l}\text { Lantai sekolah, ruang kuliah, kantor, } \\
\text { took, toserba, restoran, hotel, asrama } \\
\text { dan rumah sakit. }\end{array}$ & 250 \\
\hline
\end{tabular}

Sumber : Beton Prategang, 2001

\section{c. Pipa PVC}

Pipa PVC merupakan jenis pipa air yang biasa dipakai untuk kebutuhan sanitair, sebagai penyalur air baik itu untuk instalasi air bersih maupun instalasi air kotor. Pipa PVC memiliki berbagai macam produk dan ukuran dengan spesifikasi tertentu, sehingga dalam penggunaannya dapat disesuaikan dengan fungsi. Dalam penelitian yang dilakukan penulis pipa PVC yang digunakan merupakan produk dari PT.Wavin Duta Jaya. Dari dua jenis Standar pipa digunakan standar AW untuk penelitian yang akan dilaksanakan penulis.

Tabel 4. Tabel Pipa Wavin Standar AW

\begin{tabular}{|c|c|c|c|c|c|}
\hline \multirow{2}{*}{$\begin{array}{c}\text { CLA } \\
\text { SS }\end{array}$} & \multicolumn{2}{|c|}{ Diameter } & $\begin{array}{c}\text { Tebal } \\
\text { Dinding } \\
\text { WallnT } \\
\text { hicnes } \\
\text { (mm) }\end{array}$ & $\begin{array}{c}\text { Panjang } \\
\text { Lengan } \\
(\mathbf{m m})\end{array}$ & $\begin{array}{c}\text { Sistem } \\
\text { Sambung } \\
\text { Jointing } \\
\text { System }\end{array}$ \\
\hline \multirow{3}{*}{ AW } & $1 / 2$ & 22 & 1.5 & 4 & SC \\
& $3 / 4$ & 26 & 1.8 & 4 & SC \\
& 1 & 32 & 2.0 & 4 & SC \\
/cm 3) & $11 / 4$ & 42 & 2.3 & 4 & SC \\
& $21 / 2$ & 48 & 2.3 & 4 & SC \\
& 3 & 89 & 3.1 & 4 & SC \\
& 4 & 114 & 4.1 & 4 & SC \\
& 5 & 140 & 5.4 & 4 & SC \\
& 6 & 165 & 6.4 & 4 & SC \\
& 8 & 216 & 8.3 & 4 & SC \\
\hline
\end{tabular}

Sumber : https://rajapipa.blogspot.co.id/2014

\section{(4). Hukum Archimedes}

Hukum Archimedes merupakan suatu hukum yang menyatakan bahwa suatu benda yang sebagian atau seluruhnya dicelupkan kedalam zat cair akan mendapat gaya ke atas yang besarnya sama dengan berat zat cair yang dipindahkan oleh benda tersebut. (Asas - asas fisika, 2007).

Ada tiga keadaan benda yang tercelup dalam zat cair, yaitu terapung, melayang, dan tenggelam. Adanya tiga kemungkinan benda yang tercelup dalam zat cair disebabkan oleh gaya ke atas (gaya apung). Dengan menggunakan hukum I Newton dan hukum Archimedes, kita dapat menentukan syarat sebuah benda terapung, melayang, dan tenggelam didalam suatu zat cair.

\section{a. Terapung}

Dalam kehidupan sehari-hari dapat kita lihat benda yang terapung diatas permukaan air diantaranya diambil contoh gabus, benda seperti gabus terapung karena berat gabus tidak mampu melawan gaya apung.

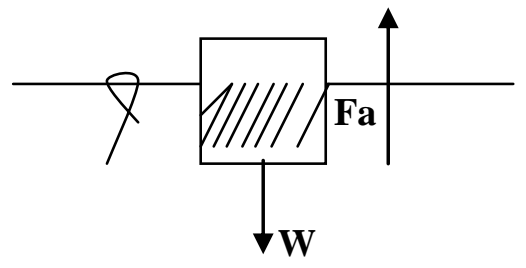

\section{Gambar 2. Benda yang sedang terapung}

$$
\begin{aligned}
& \boldsymbol{F a}=\boldsymbol{W} \\
& \text { dimana }: \mathrm{Fa}=\text { Gaya apung } \\
& \mathrm{W}=\text { Berat gabus }
\end{aligned}
$$

Pada saat terapung, besarnya gaya apung sama dengan berat gabus. Pada kondisi tersebut, hanya sebagian volume gabus yang tercelup didalam air sehingga volume air yang dipindahkan lebih kecil dari volume total gabus yang mengapung. Pada saat terapung, gabus tidak bergerak ke atas dan ke bawah. Dengan demikian digunakanlah rumus hukum I Newton pada arah vertikal.

Hukum I Newton pada arah vertikal,

$$
\begin{aligned}
& \sum F_{y}=0 \Longleftrightarrow \\
& F_{A}=\mathrm{m} \cdot \mathrm{g} \\
& \rho_{f} \mathrm{~g} V_{t}=\nabla_{\boldsymbol{b}} V_{b} \mathrm{~g} \\
& V_{t}=\frac{\rho_{b} V_{b}}{\rho_{f}}
\end{aligned}
$$

Volume benda yang tercelup $\left(\mathrm{V}_{\mathrm{t}}\right)$ lebih kecil dari pada $V_{b}$ (Volume benda total), maka syarat benda mengapung adalah :

$$
\rho_{b}<\rho_{f}
$$


Jadi, agar benda terapung massa jenis benda harus lebih kecil daripada massa jenis zat cair.

\section{b. Melayang}

Suatu benda dikatakan melayang jika, besarnya gaya apung sama dengan berat benda. Dalam keadaan itu terjadi kesetimbangan antara gaya berat dan gaya ke atas. Dengan kata lain, besarnya gaya apung sama dengan berat benda. Karena seluruh benda tercelup dalam air, maka pada peristiwa melayang volume zat cair yang dipindahkan sama dengan volume benda itu sendiri.

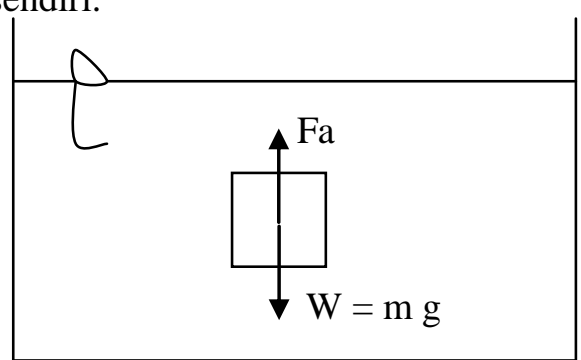

\section{Gambar 3. Benda yang sedang melayang}

Hukum I Newton pada arah vertikal,

$$
\begin{aligned}
& \sum F_{y}=0 \Longleftrightarrow \\
& F_{A}=m_{b} g \\
& \rho_{f} \mathrm{~g} V_{t}=\rho_{b} V_{b} \mathrm{~g}
\end{aligned}
$$

Pada peristiwa melayang, volume benda yang tercelup sama dengan volume benda total, sehingga syarat benda melayang adalah $\rho_{b}=\rho_{f}$

Jadi, pada benda melayang massa jenis benda sama dengan massa jenis zat cair.

\section{c. Tenggelam}

Suatu benda yang tenggelam, gaya apung besarnya lebih kecil daripada berat benda. Pada peristiwa tersebut, volume benda yang tercelup didalam zat cair sama dengan volume total benda.

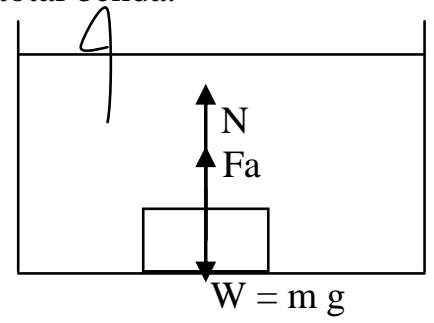

Gambar 4. Banda yang sedang tenggelam

Hukum I Newton pada arah vertikal,

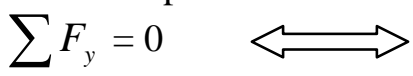

$$
\begin{aligned}
F_{A}+\mathrm{N} & =m_{b} g \\
\rho_{f} \mathrm{~g} V_{t}+\mathrm{N} & =\rho_{b} V_{b} \mathrm{~g} \\
& \mathrm{~N}=\mathrm{g}\left(\rho_{b} V_{b}-\rho_{f} V_{t}\right)
\end{aligned}
$$

Karena $\mathrm{V}_{\mathrm{t}}$ (volume benda yang tercelup) sama dengan $V_{b}$ (volume benda total), maka syarat benda tenggelam adalah :

$$
\rho_{b}>\rho_{f}
$$

Jadi, pada benda tenggelam massa jenis benda lebih besar daripada massa jenis zat cair.

\section{METODOLOGI}

Pada penelitian ini proses pelaksanaannya adalah sebagai berikut:

\section{(1). Tinjauan Pustaka}

Pelaksanaan penelitian mengacu pada studi literatur yang berhubungan langsung dengan penelitian yang nantinya akan berguna dalam mempermudah proses penelitian.

\section{(2). Survey Lapangan}

Survey di lapangan bertujuan untuk mengetahui keadaan real di lapangan, dan melakukan observasi secara langsung.

\section{(3). Perhitungan Pembebanan}

Pada tahap ini penulis menggunakan gambar untuk menghitung pembebanan yang dipakai pada rumah rakit diantaranya beban sendiri rumah, atap, dan orang yang tinggal pada rumah rakit. Berdasarkan standar pembebanan bangunan gedung yang telah ada.

\section{(4). Uji Pembebanan dan Bahan}

Dalam tahap inilah inti dari penelitian yang dilakukan penulis, yang mana terbagi dalam beberapa tahapan pekerjaan diantaranya yaitu :

a. Persiapan dan Pengadaan Bahan

Pada tahap persiapan dan pengadaan ini penulis harus sudah menyiapkan segala sesuatu yang berhubungan dengan penelitian seperti alat dan bahan yang dibutuhkan.

1. Pipa PVC 
Pipa PVC untuk pengujian ini menggunakan jenis pipa type AW dari produk Wavin, dengan dimeter luar 3". Sedangkan untuk penutup digunakan dov 3" PVC standar wavin.

2. Bambu

Bambu yang digunakan merupakan bambu jenis Manyan, bambu jenis ini merupakan jenis bambu yang kuat dan tahan lama dibandingkan dengan jenis bambu lain seperti bambu gading, bambu dabo, dan lainnya. Selain itu juga bambu jenis ini tumbuh dan mudah didapat di Sumatera khususnya Sumatera bagian Selatan. Ukuran bambu yang digunakan untuk pengujian ini dicari ukuran yang sama atau mendekati pada pipa PVC yaitu 3".

3. Tali Pengikat

Tali pengikat digunakan untuk mengikat dan menyatukan pipa PVC menggunakan karet bekas, sedangkan pada bambu menggunakan tali plastik rombe sebagai pengikat antar bambu yang akan dijadikan bahan pengujian.

4. Pengaku

Pengaku ini digunakan utuk menyatukan bambu ataupun PVC yang akan diikat, penggunaan pengaku ini terdapat untuk setiap lapisan. Pengaku ini terbuat dari potongan bambu atau potongan kayu kecil yang tebalnya lebih kurang 1 sampai $2 \mathrm{~cm}$ saja.

5. Lem dan Amplas

Lem dan amplas digunakan untuk penguatan tutup rongga pada pipa PVC yang ditutup dengan dov, agar didapat sample yang kuat dan benar-benar kedap air.

b. Pembuatan Sampel / Contoh

1. Memotong pipa PVC ikuran panjang $60 \mathrm{~cm}$ sebanyak 16 buah untuk satu buah sample, dan menutupnya dengan dov yang telah disediakan sebelumnya. Sebelum ditutup dov sebaiknya ujung pipa diamplas dan diberi lem terlebih dahulu agar dov benar-benar merekat pada pipa.

2. Memotong dan memilah bambu untuk ukuran yang sama yaitu $60 \mathrm{~cm}$. Pada bambu dicari potongan yang ketemu ruas agar bias terdapat ruang seperti PVC.

3. Jumlah bambu yang dipotong sama 16 buah untuk satu buah sampel.

4. Pengikatan sampel untuk keduan bahan yang akan diuji, untuk bambu menggunakan tali rombe dan untuk PVC menggunakan karet. Sampel yang diikat terdiri dari 4 lapis ini dikarenakan pada pondasi rumah rakit menggunakan konstruksi seperti itu juga.

5. Pada setiap lapisnya harus diberi pengaku, agar sampel tetap kaku.

6. Pastikan sampel dalam keadaan bersih dan kuat, dan sampel siap diuji.

\section{(5). Analisa Hasil dan Pembahasan}

Pada tahap ini penulis menganalisa hasil dari pengujiaan bahan yang telah dilakukan pada dua buah sampel yang berbeda, yaitu analisa dari sampel bambu dan analisa dari sampel PVC serta perbandingan dari kedua sampel bahan tersebut.

\section{ANALISA PENELITIAN (1). Detail Rumah Rakit}

Dari data dan hasil penelitian yang telah dilakukan oleh penulis didapatlah gambaran mengenai keadaan real di lapangan bentuk dan detail rumah rakit, yang terdiri atas tiga bagian diantaranya konstruksi bagian bawah, tengah, dan konstruksi bagian atas.

\section{a. Konstruksi Bagian Atas}

Pada konstruksi bagian atas ini terdiri atas seluruh bahan dan konstruksi penutup bangunan rumah rakit yang terdiri dari :

1. Kuda - kuda

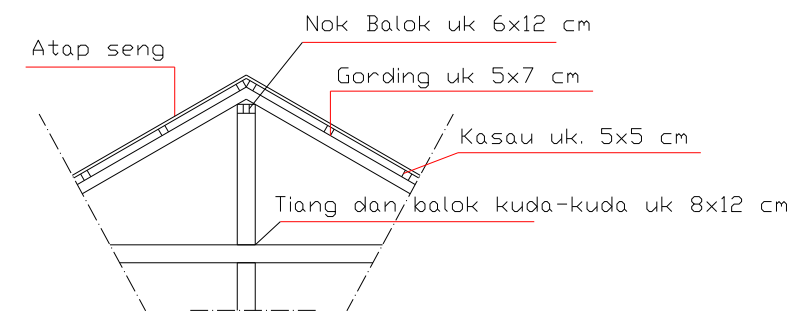

Gambar 5. Kuda-kuda rumah rakit

Kuda - kuda terdiri atas balok dan tiang dengan spesifikasi kayu kelas II jenis Merawan dengan berat maksimum 1,03 gr / cm3.

2. Gording

Gording ukuran $5 \times 7 \mathrm{~cm}$ jenis kayu sama dengan tiang dan balok kuda-kuda.

3. Reng Dudukan Seng

Reng dudukan menggunakan reng ukuran 5 $x 5 \mathrm{~cm}$ jenis Merawan

4. Seng

Seng yang digunakan adalah seng gelombang standar SNI tipe BJLS - 20K dengan berat $189 \mathrm{gr} / \mathrm{m} 2$. 
5. Tebeng Layar

Tebeng layar menggunakan papan ukuran 2 $/ 25 \mathrm{~cm}$ jenis kayu merawan kelas II.

\section{b. Konstruksi Bagian Tengah}

Pada konstruksi bagian tengah ini meliputi

beberapa bagian diantaranya

1. Kolom

Kolom pada rumah rakit menggunakan jenis kayu yang sama dengan kuda-kuda yaitu jenis merawan kelas II dengan ukuran 8 / 10 $\mathrm{cm}$.

2. Dinding

Dinding merupakan bagian dari rumah rakit yang berfungsi sebagai pelindung dan pembatas ruangan. Dinding pada rumah rakit ini menggunakan papan ukuran 2 / 25 $\mathrm{cm}$ dengan jenis kayu kelas II seperti kolom dan kuda-kuda.

3. Pagar, Pintu dan Jendela

Merupakan bagian penting dari rumah rakit yang berfungsi sebagai tempat ventilasi dan tempat keluar masuk penghuni rumah. Menggunakan kayu dari jenis merawan dengan ukuran yang bervariasi.

c. Konstruksi Bagian Bawah

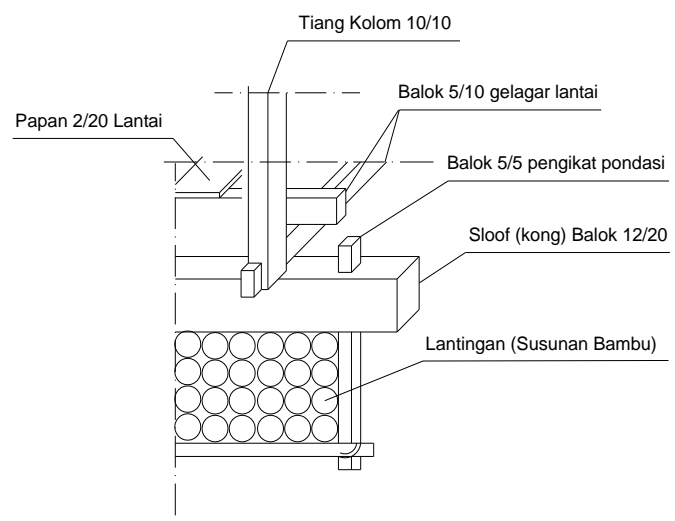

Gambar 6.Konstruksi Bagian Bawah Rumah Rakit

1. Lantai

Lantai rumah rakit terdiri atas susunan papan kelas I jenis Onglen (unglen) dengan ukuran $3 / 20 \mathrm{~cm}$.

2. Gelagar Lantai

Gelagar lantai merupakan penunjang lantai terdiri atas balok kayu (sento) ukuran 5 / 10 $\mathrm{cm}$ dari jenis kayu kelas I

3. Sloof / Kong dan Pengikat

Sloof atau Kong merupakan struktur bawah yang menopang beban keseluruhan rumah rakit yang akan diteruskan ke landasan bambu. Kong ini dibuat dari kayu kelas I jenis onglen berukuran $12 / 20 \mathrm{~cm}$

4. Bambu

Bambu merupakan struktur utama dari landasan rumah rakit, semua beban pada rumah rakit diteruskan seluruhnya ke landasan bambu. Terdiri atas susunan bambu yang telah diikat empat lapisan atau sering disebut lantingan.

\section{(2). Perhitungan Pembebanan Rumah Rakit}

Perhitungan pembebanan yang dihitung merupakan perhitungan dari detail bangunan rumah rakit yang telah diobservasi oleh penulis. Pembebanan didapat dari ukuran volume bahan dan material yang terdiri atas kayu dan bahan lainnya. Bahan dan material yang dipakai dalam penelitian penulis memiliki berat maksimum rata-rata diantaranya adalah :

- Kayu Kelas I Jenis Onglen $\quad: 1,19$ gr $/ \mathrm{cm} 3=$ $1190 \mathrm{~kg} / \mathrm{m} 3$

- Kayu Kelas II Jenis Merawan : 1,03 gr $/ \mathrm{cm} 3=$ $1030 \mathrm{~kg} / \mathrm{m} 3$

- Seng Gelombang Biasa $\quad: 189$ gr $/ \mathrm{m} 2=$ $0,189 \mathrm{~kg} / \mathrm{m} 2$

\section{a. Perhitungan Konstruksi Bagian Atas}

Perhitungan pembebanan konstruksi bagian atas merupakan jumlah dari seluruh berat bahan yang dipakai dalam konstruksi bagian atas bangunan rumah rakit.

Struktur bagian atas terdiri atas kuda kuda 4 buah, Gording, Reng dan Atap seng gelombang, menwggunakan kayu dengan kelas sama yaitu jenis kayu Merawan kelas II.

$8 / 12=34 \mathrm{~m}=(0,08 \times 0,12 \times 34 \mathrm{~m})=0,3264 \mathrm{~m} 3$.

$6 / 12=12 \mathrm{~m}=(0,06 \times 0,12 \times 12 \mathrm{~m})=0,0864 \mathrm{~m} 3$.

$5 / 7=54,4 \mathrm{~m}=(0,05 \times 0,07 \times 54,4 \mathrm{~m})=0,1904 \mathrm{~m} 3$.

$5 / 5=216 \mathrm{~m}=(0,05 \times 0,05 \times 216 \mathrm{~m})=0,54 \mathrm{~m} 3$.

Seng Gelombang $=163,2 \mathrm{~m} 2$

Total Kayu $=1,1432 \mathrm{m3}$

Berat Struktur Atas $=($ total kayu $\mathrm{x}$ berat kayu $)$

$+($ total seng $\mathrm{x}$ berat $)$

$=(1,1432 \mathrm{~m} 3 \times 1030 \mathrm{~kg} / \mathrm{m} 3)+(163,2 \mathrm{~m} \times 0,189 \mathrm{~kg}$

$/ \mathrm{m} 2)$

$=(1177 \mathrm{~kg}+30,845 \mathrm{~kg})$

$=1207,845 \mathrm{~kg}$.

b. Perhitungan Konstruksi Bagian Tengah

Perhitungan pembebanan konstruksi bagian tengah merupakan jumlah dari seluruh berat bahan yang dipakai dalam konstruksi bagian tengah bangunan rumah rakit. 
Struktur bagian tengah terdiri atas kolom, dinding, serta penunjang seperti pintu, jendela, dan pagar. Semua menggunakan kayu dengan kelas sama yaitu jenis kayu Merawan kelas II. Papan $2 / 25=142,07 \mathrm{~m} 2 \times 0,02 \mathrm{~m}=2,84 \mathrm{~m} 3$ $10 / 10=114 \mathrm{~m} \times 0,1 \mathrm{~m} \times 0,1 \mathrm{~m}=1,14 \mathrm{~m} 3$

$$
\begin{aligned}
6 / 10= & 49,94 \mathrm{mx} 0,06 \mathrm{~m} \times 0,1 \mathrm{~m} \\
= & 0,29 \mathrm{~m} 3 \\
5 / 10= & 48,8 \mathrm{~m} \times 0,05 \mathrm{~m} \times 0,1 \mathrm{~m} \\
= & 0,244 \mathrm{~m} 3 \\
2,5 / 10 & =62,8 \mathrm{~m} \times 0,025 \mathrm{~m} \times 0,1 \mathrm{~m} \\
& =0,157 \mathrm{~m} 3 \\
3 / 6 & =80,65 \mathrm{~m} \times 0,03 \mathrm{~m} \times 0,06 \mathrm{~m} \\
& =0,145 \mathrm{~m} 3
\end{aligned}
$$

Total Kayu dan Papan yang digunakan

$$
=4,816 \mathrm{m3}
$$

Total Berat Konstruksi Bagian Tengah

$$
\begin{aligned}
& =(4,816 \mathrm{~m} 3 \times \text { Berat kayu }) \\
& =(4,816 \mathrm{~m} 3 \times 1030 \mathrm{~kg} / \mathrm{m} 3) \\
& =\mathbf{4 9 6 0 , 4 8} \mathbf{~ k g}
\end{aligned}
$$

\section{c. Perhitungan Konstruksi Bagian Bawah}

Perhitungan pembebanan konstruksi bagian bawah merupakan jumlah dari seluruh berat bahan yang dipakai dalam konstruksi bagian bawah bangunan rumah rakit.

Struktur bagian bawah terdiri atas Sloof (Kong), Gelagar Lantai, serta Lantai. Untuk konstruksi bawah menggunakan kayu dengan kelas yang lebih baik dan kuat dengan tujuan agar dapat tahan lebih lama yaitu jenis kayu Onglen kelas I.

Papan $2 / 20=108 \mathrm{~m} 2 \times 0,02 \mathrm{~m}=2,16 \mathrm{~m} 3$

$12 / 10=40 \mathrm{~m} \times 0,12 \mathrm{~m} \times 0,2 \mathrm{~m}=0,96 \mathrm{~m} 3$

$5 / 10=108 \mathrm{~m} \times 0,05 \mathrm{~m} \times 0,1 \mathrm{~m}=0,54 \mathrm{~m} 3$

Total Kayu dan Papan yang digunakan $=\mathbf{3 , 6 6}$ m3

Total Berat Konstruksi Bagian Bawah

$=(3,66 \mathrm{~m} 3 \times$ Berat kayu $)$

$=(3,66 \mathrm{~m} 3 \times 1190 \mathrm{~kg} / \mathrm{m} 3)$

$=4355,4 \mathrm{~kg}$

Jadi, total perhitungan pembeban pada rumah rakit adalah :

$=(1207,8 \mathrm{~kg}+4960,4 \mathrm{~kg}+4355,4 \mathrm{~kg})$

$=10523,6 \mathrm{~kg}$

\section{(3). Hukum Archimedes}

Dalam pengujian ini diperhitungkan juga pengapungan rumah rakit yang telah dihitung, yaitu dengan membandingkan perhitungan dengan hukum Archimedes.

$\boldsymbol{F a}=\boldsymbol{W} \quad \boldsymbol{W}=\boldsymbol{m} \cdot \mathrm{g}$
$=\{(1,1432 \mathrm{~m} 3 \times 1030 \mathrm{~kg} / \mathrm{m} 3)+(163,2 \mathrm{~m} 2 \times$ $0,189 \mathrm{~kg} / \mathrm{m} 2)+(4,816 \mathrm{~m} 3 \times 1030 \mathrm{~kg} / \mathrm{m} 3)+$ $(3,66 \mathrm{~m} 3 \times 1190 \mathrm{~kg} / \mathrm{m} 3)\}$

$=10523,6 \mathrm{~kg}$

$\mathrm{Nb}$ : Berat kayu yang digunakan sudah termasuk gravitasi.

$\boldsymbol{F} \boldsymbol{a}=\boldsymbol{m} \cdot \boldsymbol{g}$

$=(\boldsymbol{V}$. Bj pipa $) \cdot g$

$=(900$ btg $\times 8,806 \times 9,8)$

$=77668,92 \mathrm{~kg}$

$\mathrm{Nb}: \mathrm{Bj}$ pipa $\mathrm{PVC}=8,806 \mathrm{~kg} / \mathrm{btg}$

Jadi dari hasil perhitungan dapat dilihat bahwa

$\boldsymbol{F a} \geq \boldsymbol{W}$ jadi konstruksi rumah rakit yang

dihitung mengapung

\section{(4). Pengujian Bahan}

Pengujian dilakukan dengan menggunakan dua bahan yang berbeda diantaranya adalah Bambu dan Pipa PVC yang disusun sama dengan ukuran yang sama pula.

\begin{tabular}{|c|c|c|c|c|}
\hline \multirow{2}{*}{$\begin{array}{l}\text { NAMA } \\
\text { BAHAN }\end{array}$} & \multicolumn{4}{|c|}{ DAYA APUNG DI ATAS AIR } \\
\hline & $\begin{array}{l}\text { BEBAN } \\
2 \mathrm{KG}\end{array}$ & $\begin{array}{l}\text { BEBAN } \\
8 \mathrm{KG}\end{array}$ & $\begin{array}{l}\text { BEBAN } \\
10 \mathrm{KG}\end{array}$ & $\begin{array}{l}\text { BEBAN } \\
\text { SENDIRI }\end{array}$ \\
\hline $\begin{array}{l}\text { BAMBU } \\
\text { (Penampang }\end{array}$ & $\begin{array}{c}10 \mathrm{CM} \\
9 \mathrm{CM}\end{array}$ & $\begin{array}{l}8 \mathrm{CM} \\
5 \mathrm{CM}\end{array}$ & $\begin{array}{l}4 \mathrm{CM} \\
2 \mathrm{CM}\end{array}$ & $\begin{array}{l}19 \mathrm{CM} \\
17 \mathrm{CM}\end{array}$ \\
\hline Rata - rata & $\begin{array}{l}8 \mathrm{CM} \\
9 \mathrm{~cm}\end{array}$ & $\begin{array}{l}3 \mathrm{CM} \\
5 \mathrm{~cm}\end{array}$ & $\begin{array}{l}1 \mathrm{CM} \\
2 \mathrm{~cm}\end{array}$ & $\begin{array}{l}13 \mathrm{CM} \\
16 \mathrm{~cm}\end{array}$ \\
\hline
\end{tabular}

\section{a. Bambu}

Pengujian bambu dilakukan dengan membuat dua buah sampel dari bambu ukuran panjang $60 \mathrm{~cm}$ sampai luar ruas diameter ratarata $3 "( \pm 8 \mathrm{~cm})$ dengan disusun sama seperti keadaan landasan rumah rakit yang telah diobservasi sebelumnya oleh penulis. Dari hasil uji coba bahan menggunakan bambu didapat hasil sebagai berikut:

Tabel 5. Daya Apung Bambu Terhadap Beban Di Atas Air

Dari tabel diatas uji coba pada bambau dipakai dengan mengunakan luasan bambu dak kuat tekan apung dari permukaan air yang dilakukan pada pengujian didalam air sehingga didapat hasil yang terdapat ditabel

\section{b. Pipa PVC}

Pengujian Pipa PVC dilakukan dengan membuat sampel dari Pipa jenis PVC merk Wavin ukuran panjang $60 \mathrm{~cm}$ diameter 3 " dilengkapi dove sebagai penutup lobang pada pipa dengan disusun sama seperti keadaan 
landasan rumah rakit yang telah diobservasi sebelumnya oleh penulis. Dari hasil uji coba bahan menggunakan Pipa PVC didapat hasil sebagai berikut :

Tabel 6. Daya Apung Pipa PVC Wavin

Terhadap Beban Di Atas Air

\begin{tabular}{|c|c|c|c|c|}
\hline \multirow{2}{*}{$\begin{array}{l}\text { NAMA } \\
\text { BAHAN }\end{array}$} & \multicolumn{4}{|c|}{ DAYA APUNG DI ATAS AIR } \\
\hline & $\begin{array}{c}\text { BEBAN } \\
2 \mathrm{KG}\end{array}$ & $\begin{array}{c}\text { BEBAN } \\
8 \mathrm{KG}\end{array}$ & $\begin{array}{c}\text { BEBAN } \\
10 \mathrm{KG}\end{array}$ & $\begin{array}{l}\text { BEBAN } \\
\text { SENDIRI }\end{array}$ \\
\hline Pipa PVC & $28 \mathrm{CM}$ & $25 \mathrm{CM}$ & $23 \mathrm{CM}$ & $30 \mathrm{CM}$ \\
\hline Wavin (AW) & $27 \mathrm{CM}$ & $25 \mathrm{CM}$ & $22 \mathrm{CM}$ & $30 \mathrm{CM}$ \\
\hline (Penampang 60 & $28 \mathrm{CM}$ & $25 \mathrm{CM}$ & $23 \mathrm{CM}$ & $30 \mathrm{CM}$ \\
\hline $\begin{array}{c}\times 30 \mathrm{~cm}) \\
\text { Rata }- \text { rata }\end{array}$ & $27,5 \mathrm{~cm}$ & $25 \mathrm{~cm}$ & $22,5 \mathrm{~cm}$ & $30 \mathrm{~cm}$ \\
\hline
\end{tabular}

Dari tabel diatas daya tekan pipa yang bisa digunakan terdapat pada daya dukung yang dikeluarkan oleh produk pipa PVC pada tabel 4 . Kemudian peneliti melakukan pengujian dengan memberikan beban dan memperoleh hasil daya apung berat sendiri sebesar $30 \mathrm{~cm}$

\section{(5). Analisa Hasil Daya Apung}

Dari hasil pengujian dan penelitian di lapangan didapatlah analisa bahwa landasan dari pipa PVC jauh lebih besar daya apungnya dibandingkan bahan dari bambu.

Untuk pembebanan rumah rakit seluruhnya di lapangan landasan bambu penampang $12 \mathrm{~m} \mathrm{x}$ $9 \mathrm{~m}$ dapat memikul total beban sebesar 10523,6 $\mathrm{kg}$ dengan daya apung bambu di atas air setinggi $16 \mathrm{~cm}$.

Dari hasil perhitungan beban total rumah rakit dan daya apung bambu di lapangan dapat ditarik kesimpulan bahwa dengan menggunakan pipa PVC lapisan pada landasan rumah rakit bisa mengalami pengurangan, namun akan lebih baik jika tetap disusun 4 lapis selain akan tampak lebih kokoh juga menimbulkan arsitektur tersendiri.

\section{(6). Keamanan Dan Keawetan Bahan}

\section{Keamanan}

Keamanan pada landasan dipengaruhi oleh kekuatan dan ketahanan bahan terhadap beban yang dipikul. Pada bambu kekuatannya relatif, bila dalam keadaan baru bambu bisa dikatakan kuat dan jika sudah terkena cuaca dan dalam waktu tertentu bambu harus diganti dan akan mengalami kerusakan. Berbeda dengan pipa PVC merk Wavin dari bahannya saja sudah dipastikan pipa ini tahan terhadap air dan memiliki daya dukung beban sebesar 5 sampai dengan $10 \mathrm{~kg} / \mathrm{cm} 3$.
2. Keawetan Bahan

Landasan bambu pada rumah rakit rata-rata di dapat dari data survey lapangan mengalami penggantian lapisan 3 sampai 5 tahun sekali. Ini dikarenakan bambu di dalam air menjadi sarang udang yang menyebabkan bambu lama kelamaan rusak dan mengalami pergantian. Berbeda dengan pipa PVC yang memang dibuat untuk tahan air, dan pada ujung pipa ditutup dengan penutup yang tidak memungkinkan hewan sungai seperti udang untuk bersarang. Dan ketahanan pipa dipastikan lebih dari 5 tahun bahkan bisa mencapai 10 tahunan.

\section{KESIMPULAN DAN SARAN (1). Kesimpulan}

Dari hasil penelitian ini penulis dapat menyimpulkan bahwah dengan mengunakan bahan pipa PVC memiliki ketahanan yang relatif lebih lama dibandingkan dengan pengunaan bahan bambu, yang mana ketahanan pipa PVC bisa bertahan selama 10 tahun sedangkan bambu hanya bisa bertahan 3 sampai 5 tahun. Dengan menggunakan Pipa PVC pekerjaan pondasi bisa lebih mudah dan lebih ringan. Kemampuan pipa PVC memiliki daya dukung beban 5 (lima) kali leih besar dibandingkan dengan bahan bambu. Maka dari itu pipa PVC bisa dipakai sebagai pondasi pada rumah rakit dan bahan nya mudah didapat dipasaran mengingat keberadaan bambu sudah sulit didapat.

\section{(2). Saran}

Menyarankan agar penelitian lain dapat mengembangkan mencari alternatif lain untuk konstruksi rumah rakit pada Sekitaran sungai musi Palembang.

\section{DAFTAR PUSTAKA}

https://rajapipa.blogspot.co.id//2014(diakses pada hari , tanggal 28 April 2017 pukul 08.44 WIB)

Laporan Jurnalistik Kompas, 2010, "Jelajah Musi” PT. Kompas Media Nusantara, Jakarta. melayuonline.com (diakses pada hari, tanggal 28 April 2017 pukul 12.30 WIB)

Melalatoa, Junus, 1995, "Ensiklopedi Suku Bangsa di Indonesia", PT. Eka Putra, Jakarta. Nawi G, Edward, 2001, "Beton Prategang", Erlangga, Jakarta.

Ruwanto, Bambang, 2007, "Asas-asas Fisika", Yudistira, Bogor. 